CAROLINA HOMEM DE MELLO REINACH

Áreas contaminadas:

tendências de reabilitação e reparação

Dissertação de Mestrado

Orientadora: Profa. Associada Dra. Ana Maria de Oliveira Nusdeo

UNIVERSIDADE DE SÃO PAULO

FACULDADE DE DIREITO

São Paulo-SP

2018 



\section{Áreas Contaminadas: \\ tendências de reabilitação e reparação}

Dissertação apresentada a Banca Examinadora do Programa de Pós-Graduação em Direito, da Faculdade de Direito da Universidade de São Paulo, como exigência parcial para obtenção do título de Mestre em Direito, na área de concentração ambiental, sob a orientação da Professora Associada Dra. Ana Maria de Oliveira Nusdeo

\section{UNIVERSIDADE DE SÃO PAULO}

FACULDADE DE DIREITO

São Paulo-SP

2018 
Reinach, Carolina Homem de Mello

Áreas contaminadas: tendências de reabilitação e reparação / Carolina Homem de Mello Reinach ; orientadora Ana Maria de Oliveira Nusdeo -- São Paulo, 2018.

106

Dissertação (Mestrado - Programa de Pós-Graduação em Direito Direito Econômico, Financeiro e Tributário) - Faculdade de Direito, Universidade de São Paulo, 2018.

1. Direito ambiental. 2. Gerenciamento de áreas contaminadas. 3. Metas de reabilitação. 4. Reparação integral. 5. Direito ambiental alemão. I. Nusdeo, Ana Maria de Oliveira, orient. II. Título. 
REINACH, Carolina Homem de Mello. Áreas Contaminadas: tendências de reabilitação e reparação. 2018. 106 f. Mestrado - Faculdade de Direito, Universidade de São Paulo, São Paulo, 2018.

O gerenciamento de áreas contaminadas previsto na Lei 13.577/09 do Estado de São Paulo estabeleceu procedimentos para a prevenção, identificação e reabilitação de tais áreas. Tais procedimentos foram desenvolvidos em linha com a experiência internacional envolvendo áreas contaminadas, contando com o suporte técnico do governo alemão. Críticos ao modelo estabelecido sustentam que a sistemática estaria aquém da proteção ambiental assegurada pelo ordenamento jurídico brasileiro e violaria princípios basilares do direito ambiental. Para contribuir com a discussão, esse trabalho procurou conhecer um pouco da experiência internacional, principalmente da experiência alemã, para verificar os elementos que teriam sido considerados na concepção do modelo de gerenciamento de áreas contaminadas ora adotado. Procurou-se também estudar normas brasileiras sobre dano ambiental e sua reparação, bem como os princípios de direito ambiental pertinentes e normas sobre a função social da propriedade, para discutir a sua relação de compatibilidade com o modelo de gerenciamento de áreas contaminadas adotado.

Palavras-chave: Direito ambiental, gerenciamento de áreas contaminadas, metas de reabilitação, reparação integral, direito ambiental alemão. 


\begin{abstract}
REINACH, Carolina Homem de Mello. Contaminated areas: rehabilitation and repair trends. 2018. 106 p. Master - Faculty of Law, University of São Paulo, São Paulo, 2018.

The management of contaminated areas provided for in Law 13,577/09 of the State of Sao Paulo established procedures for the prevention, identification and rehabilitation of such areas. Such procedures were developed according to the international experience involving contaminated areas, with technical support from the German government. Critics of the established model argue that the system would fall short of the environmental protection guaranteed by the Brazilian legal system and would violate basic principles of environmental law. To contribute to the discussion, this work intends to verify the international experience, mainly the German experience, to understand the elements that would have been considered in the conception of the model of management of contaminated areas adopted in Law 13,577/09. It also intends to study Brazilian norms on environmental damage and its repair, as well as the pertinent environmental law principles and norms on the social function of property, to discuss their compatibility relation with the adopted model of management of contaminated areas.
\end{abstract}

Keywords: Environmental law, management of contaminated areas, rehabilitation goals, integral reparation, German environmental law. 
Ao Tom, meu grande companheiro. 


\section{AGRADECIMENTOS}

Agradeço à minha orientadora, Profa. Dra. Ana Maria de Oliveira Nusdeo, pela oportunidade de realizar esse projeto e pela confiança depositada; e aos Drs. Ana Luiza Silva Spínola e Reginaldo Antonio Bertolo, pela dedicada participação no Exame de Qualificação.

Agradeço também aos colegas do escritório, principalmente ao Oscar Graça Couto, Guilherme Junqueira de Sousa Leal, Pedro Marino Bicudo e Mariana Fernandes Miranda, pelo apoio, exemplo e contribuições de mérito para esse trabalho.

Agradeço ainda ao Prof. Dr. Jens Kersten, por ajudar a viabilizar a pesquisa sobre áreas contaminadas na Faculdade de Direito da LudwigMaximilians-Universität de Munique, na Alemanha.

Finalmente, agradeço ao meu marido, pelo entusiasmo, cumplicidade e zelo; e aos familiares e amigos, pela referência, amor e preenchimento. 


\section{SUMÁRIO}

1. INTRODUÇÃO..............................................................................................11

2. GERENCIAMENTO DE ÁREAS CONTAMINADAS NO BRASIL............................15

2.1. Percepção dos problemas envolvendo áreas contaminadas........................... 15

2.2. Concepção do modelo de gerenciamento e produção normativa...................... 19

2.3. Análise do modelo paulista ................................................................. 24

2.4. Questionamento quanto aos limites aceitáveis de contaminação...................... 30

2.4.1. Considerações de ordem técnica ........................................................... 31

2.4.2. Valores de Prevenção e a introdução de contaminantes no solo ................ 32

2.4.3. Avaliação de Risco e a Reabilitação para o uso declarado ......................... 34

2.4.4. Vulnerabilidade dos ecossistemas atingidos .......................................... 36

2.4.5. Ações civis públicas ..................................................................... 36

2.4.6. Incidente de resolução de demandas repetitivas..................................... 39

3. GERENCIAMENTO DE ÁREAS CONTAMINADAS EM OUTROS PAÍSES.............41

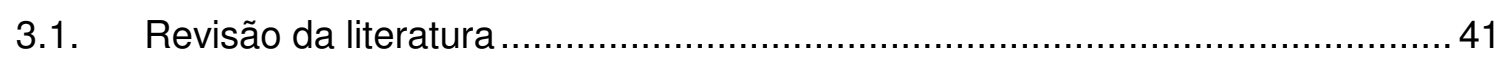

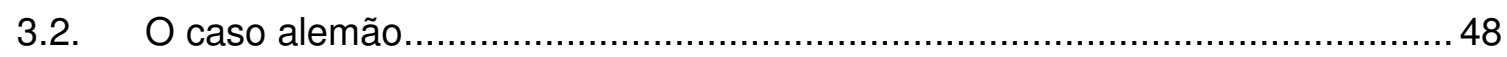

3.2.1. Necessidade de normas para a proteção do solo.................................... 51

3.2.2. Custos envolvidos nos processos de reabilitação ................................... 53

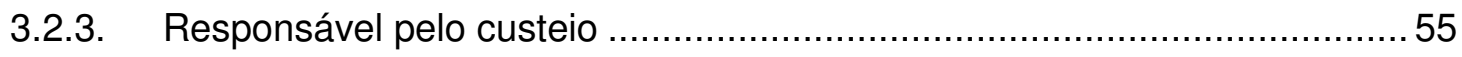

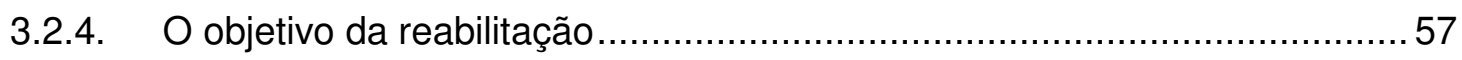

3.2.4.1. As diferentes funções do solo e a sua proteção ............................... 57

3.2.4.2. Dificuldades relacionadas à descontaminação.................................. 59

3.2.4.3. O afastamento do perigo (Gefahrenabwehr) como meta....................60

3.2.4.3.1. Uso futuro do imóvel ....................................................... 61

3.2.4.3.2. Avaliação do risco (Gefährdungsabschätzung) .........................62 62

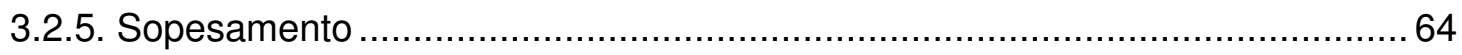

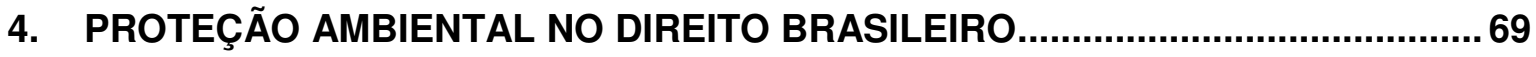

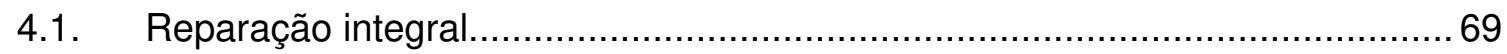

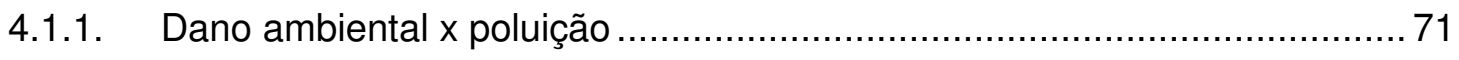

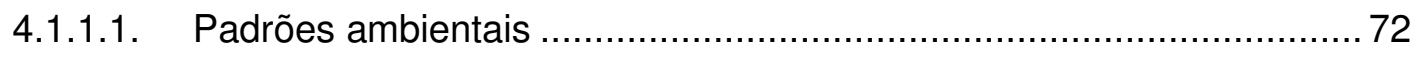

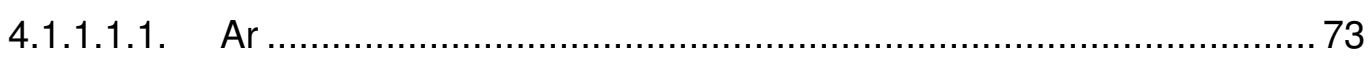

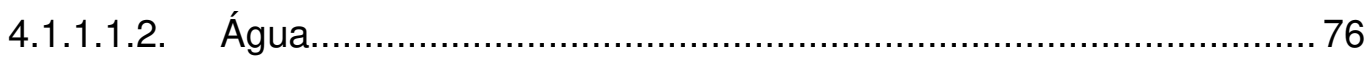

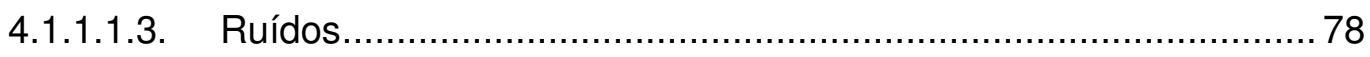

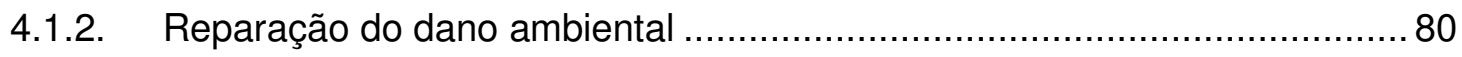

4.1.2.1. Recuperação de áreas degradadas ............................................... 80

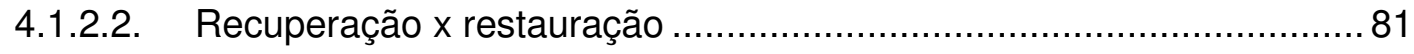

4.1.2.3. Recomposição ................................................................ 81 


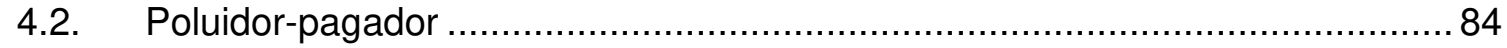

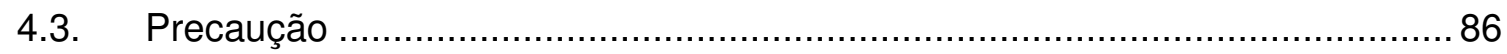

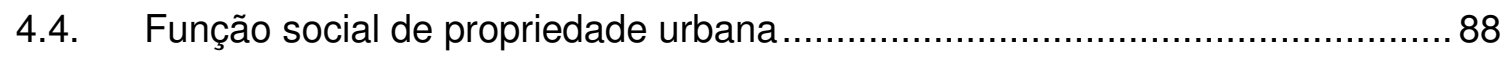

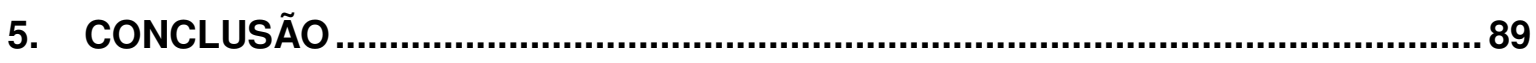

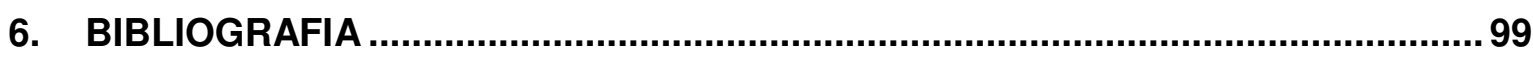




\section{INTRODUÇÃO}

Tendo em vista os prejuízos que as áreas contaminadas podem trazer à saúde humana e ao meio ambiente, tornou-se necessário o desenvolvimento de sistemática para a prevenção, identificação e reabilitação de tais áreas.

As normas que disciplinam a questão hoje no Brasil ${ }^{1}$ estabelecem rotinas e procedimentos essencialmente semelhantes, visando não só ao controle da qualidade do solo e da água subterrânea, mas também à informação da população e do Poder Público, de forma a garantir a segurança da utilização da área.

Nesse contexto, o responsável pela área deverá reunir informações sobre a utilização pretérita do imóvel e realizar estudos para verificar eventual presença de contaminantes no solo e na água subterrânea e suas características. A depender da concentração dos contaminantes identificados, deverá realizar avaliação de risco para caracterizar e quantificar o risco oferecido a eventuais receptores expostos.

Com base no resultado de tais estudos - principalmente no da avaliação de risco - será avaliada a necessidade de implantação de medidas de intervenção na área.

Vale destacar que a simples constatação de contaminantes no solo ou nas águas subterrâneas, a rigor, não seria suficiente para tornar a intervenção exigível, sendo necessária a verificação de efetivo risco à saúde humana ou ao meio ambiente.

Importa esclarecer ainda que a intervenção não significa, necessariamente, a completa remoção do solo contaminado ou a recuperação da qualidade original da água subterrânea impactada, objetivando apenas o alcance de níveis toleráveis de risco que viabilizem o uso declarado ou pretendido para a área. Assim, ainda que a remoção deva ser priorizada, medidas de contenção de contaminantes poderão ser aceitas, bem como medidas de engenharia e de controle institucional (restrições de uso, etc.).

1 No âmbito federal: Resolução 420/09 do CONAMA; no Estado de São Paulo: Lei 13.577/09, Decreto 59.263/13 e Decisão de Diretoria 38/17 da CETESB; no Estado de Minas Gerais: Deliberação Normativa Conjunta 02/10 do COPAM/CERH. 
Tal sistemática tem sido alvo de críticas, principalmente quanto à exigibilidade de medidas de intervenção e ao alcance de tais medidas.

$\mathrm{Na}$ visão dos críticos, os contaminantes deveriam ser removidos tanto quanto possível, independentemente de, no caso concreto, oferecerem riscos aos eventuais receptores expostos ou não. Ao admitir a permanência de contaminantes no solo e na água subterrânea, as normas não garantiriam a proteção ao meio ambiente, tal como prevista no ordenamento jurídico brasileiro, violando o princípio da reparação integral do dano, o princípio da precaução e o princípio do poluidor-pagador.

O debate, hoje, é incipiente, bastante marcado pela atuação do Ministério Público do Estado de São Paulo ("MPSP") junto à Companhia Ambiental do Estado de São Paulo ("CETESB") e ao Tribunal de Justiça do Estado de São Paulo ("TJSP"). As normas da legislação paulista foram questionadas por meio de ação direta de inconstitucionalidade, de ações civis públicas e de incidente de resolução de demandas repetitivas. Tais ações ainda estão em curso, não havendo ainda entendimento consolidado sobre o assunto.

A discussão a respeito do gerenciamento de áreas contaminadas e dos limites de contaminação legalmente aceitáveis é importante não só para legitimar (ou não) a sua adoção, como para aperfeiçoar o modelo adotado. A única lei existente no território brasileiro sobre o assunto é a do Estado de São Paulo - Lei SP 13.577/09 -, não havendo ainda outras leis estaduais ou mesmo lei federal sobre o tema ${ }^{2}$. Trata-se, portanto, de uma oportunidade para ampliar e amadurecer a discussão, contribuindo para a construção de um modelo consistente e adequado, inclusive no nível nacional.

Nesse contexto, e dada a contundência das críticas, esse trabalho pretende (i) identificar os motivos que levaram ao desenvolvimento de um modelo de gerenciamento de áreas contaminadas baseado no controle de risco e (ii) contribuir para a reflexão sobre eventual respaldo que tal modelo encontraria no ordenamento jurídico brasileiro.

2 Embora o Conselho Nacional do Meio Ambiente ("CONAMA") e os conselhos estaduais de Minas Gerais tenham disciplinado o assunto dentro de suas competências, suas normas não têm força de lei. 
No Capítulo 2, para a melhor compreensão do problema de pesquisa, será analisada a legislação brasileira sobre áreas contaminadas, principalmente no que se refere às definições de "quando" e "quanto" intervir. Tal análise deverá ser precedida da contextualização histórica, desde a percepção dos problemas relacionados à contaminação do solo e das águas subterrâneas, até a capacitação dos órgãos ambientais e a concepção do gerenciamento de áreas contaminadas.

A legislação paulista será objeto de mais atenção, uma vez que foram essencialmente os seus termos e a sua aplicação que deram origem aos questionamentos aqui tratados.

A caracterização da crítica ao modelo ora discutido envolverá: (i) considerações de ordem técnica (não jurídicas), (ii) a ação direta de inconstitucionalidade que questionou dispositivos da Lei SP 13.577/09; (iii) artigos publicados sobre o tema das áreas contaminadas e seu tratamento jurídico no Brasil; (iv) as teses veiculadas nas ações civis públicas e no incidente de resolução de demandas repetitivas.

No Capítulo 3, e como o modelo brasileiro parece acompanhar o modelo adotado, há mais tempo, em outros países, tendo sido desenvolvido com o apoio técnico do governo alemão, a evolução do tema em âmbito internacional também será objeto de atenção.

O estudo da evolução das políticas voltadas à reabilitação de áreas contaminadas no cenário internacional será feito por meio do relato da literatura reunida, não se fazendo propriamente uma imersão na legislação de países específicos. Serão mencionados os casos dos Estados Unidos da América ("EUA") e da Holanda, muito em função do seu pioneirismo no enfrentamento do problema (outros países da Europa Ocidental serão tratados genericamente). O objetivo será verificar os motivos que levaram à concepção de modelos de gerenciamento baseados na avaliação e controle do risco.

Ainda, como o modelo de gerenciamento de áreas contaminadas previsto na legislação brasileira teve por base o procedimento adotado na Alemanha, o contexto alemão será objeto de um estudo mais aprofundado. 0 objetivo será verificar como a evolução do assunto se deu nesse país, técnica 
e juridicamente, e quais elementos foram considerados para se chegar ao modelo de gerenciamento hoje estabelecido.

Ao final, o Capítulo 4 se voltará para o ordenamento jurídico brasileiro e paulista, com o estudo sobre princípios do direito ambiental e normas sobre dano ambiental, sua reparação e o exercício da função social da propriedade urbana. $O$ objetivo será verificar o nível de proteção ambiental estabelecido, para posterior reflexão quanto à sua compatibilidade com o modelo de gerenciamento de áreas contaminadas ora discutido.

O método central do trabalho é o dogmático, na medida em que se procura compreender um conjunto normativo (relativo a áreas contaminadas), sua racionalidade e sua eventual compatibilidade com o ordenamento jurídico. $O$ trabalho se valerá também do método comparado, já que as normas do gerenciamento alemão também serão objeto de estudo. 


\section{CONCLUSÃO}

Como antecipado, esse trabalho se propôs a (i) identificar os motivos que levaram ao desenvolvimento de um modelo de gerenciamento de áreas contaminadas baseado no controle de risco e (ii) contribuir para a reflexão sobre eventual respaldo que tal modelo encontraria no ordenamento jurídico brasileiro.

Como visto no Capítulo 2, além de importante para evitar a exposição a contaminantes, a reabilitação de áreas contaminadas é tida como estratégica para a sustentabilidade urbana. De um lado, a reutilização de áreas contaminadas contribui para a revitalização da região e para a diminuição de vazios urbanos; de outro, permite a otimização da infraestrutura já instalada e evita a busca de novos imóveis em áreas de expansão urbana.

No caso da Alemanha, que se viu diante de um enorme passivo, da necessidade de reconstruir o país após a reunificação e de um movimento de urbanização que ameaçava as áreas verdes, a reutilização de áreas contaminadas ganhou relevância.

Os custos envolvidos nos processos de reabilitação, porém, sobretudo no emprego de técnicas que visam à remoção completa dos contaminantes, são muito altos. $E$, diante da dificuldade de se identificar aqueles que deram origem à contaminação (e de encontra-los solventes), tais custos terminam por recair sobre o Poder Público.

Nos casos aqui estudados, os governos, obrigados a eleger prioridades para a destinação de seus recursos, ponderaram que, além de garantir a reutilização segura dos imóveis contaminados, era importante observar a proporcionalidade entre os valores dispendidos e os benefícios ambientais alcançados. Nesse contexto, um modelo de gerenciamento de áreas contaminadas baseado no controle de risco poderia garantir a segurança necessária sem comprometer as finanças públicas e, ainda, atrair recursos privados.

Esses seriam, em síntese, méritos importantes de tal modelo: viabilizar a reutilização segura de imóveis contaminados sem comprometer o gasto público de forma considerada irracional. 
No Brasil, a adoção de um modelo de gerenciamento orientado pelo controle de risco não partiu propriamente de um diagnóstico interno que revelasse a composição natural dos diferentes tipos de solo, o número de áreas contaminadas do território, os custos envolvidos na sua reabilitação ou nos prejuízos decorrentes da sua manutenção.

Embora o Ministério da Saúde indique a existência de mais de 12.000 áreas com populações expostas ou potencialmente expostas a contaminantes químicos no Brasil, ${ }^{290}$ os órgãos ambientais cadastraram apenas 6.645 áreas contaminadas e reabilitadas (distribuídas entre os Estados de São Paulo, Rio de Janeiro e Minas Gerais), não se sabendo ao certo o tamanho do passivo nem suas características.

De todo o modo, o conhecimento da experiência internacional pode ser proveitoso para identificar soluções para problemas comuns, evitar a reprodução de tentativas mal sucedidas ou, ao menos, ter consciência dos desafios a elas relacionados.

O estudo alemão pode trazer contribuições valiosas para a discussão brasileira sobre o gerenciamento de áreas contaminadas:

Em primeiro lugar, é interessante a provocação quanto à relação de proporcionalidade existente entre o benefício obtido por meio das diferentes metas de reabilitação (remoção de contaminantes, controle do risco, etc.) e os respectivos custos. ${ }^{291}$

Embora a discussão dos custos envolvidos na reparação de danos ambientais possa parecer menor diante da importância do meio ambiente, no contexto de áreas contaminadas é elemento central, que não pode ser desconsiderado na formulação das políticas públicas. Independentemente da

290 Dados do Sistema de Informação de Vigilância em Saúde de Populações Expostas a Áreas Contaminadas - SISSOLO do Ministério da Saúde, disponíveis em <http://u.saude.gov.br/index.php/o-ministerio/principal/leia-mais-o-ministerio/1116-secretariasvs/vigilancia-de-a-a-z/contaminantes-quimicos/16159-vigipeq-vigisolo-contaminantesquimicos>. Último acesso em 05.01.18.

291 "Há de se convir que existe um dever do Estado em agir para proteger o meio ambiente. Embora seja certa a vedação de tutela insuficiente do meio ambiente, por outro lado, há a proibição de intervenção excessiva. (...) ante a proibição de excesso e a proibição de insuficiência, surgem para o legislador ordinário possibilidades de variação em aberto e somente se houver manifesta insuficiência da proteção é que há inconstitucionalidade" (TJSP, Apelação oํ 1032789-75.2013.8.26.0100, Des. Ruy Alberto Leme Cavalheiro, 1a Câmara Reservada ao Meio Ambiente, j. 03.03.16). 
origem dos recursos (privados ou públicos), a ponderação sobre a racionalidade do gasto é pertinente. ${ }^{292}$

Em segundo lugar, é pertinente a reflexão sobre as diferentes funções do solo e a sua proteção. A percepção de que o solo não desempenha apenas funções naturais, sendo intensamente utilizado pela população para diversos fins (moradia, sistema viário, atividades agropecuárias, depósito de resíduos, etc.), evidencia o desafio de um sistema de proteção que pretenda assegurar o exercício das funções naturais do solo em todo o território. ${ }^{293}$ Afinal, a impermeabilização, ocupação e exploração do solo - e não apenas a presença de contaminantes - também podem alterar suas características originais. ${ }^{294}$

Quanto ao nível de proteção ambiental exigido pelo ordenamento jurídico brasileiro e eventual incompatibilidade com um gerenciamento de áreas contaminadas orientado pelo controle de risco, que admite a permanência de contaminantes no solo e nas águas subterrâneas, ponderamos o seguinte:

Como visto no item 4.1.1., o direito brasileiro não proíbe a presença de contaminantes no meio ambiente, admitindo expressamente, inclusive, o lançamento de substâncias no ar e nos recursos hídricos, desde que observadas as concentrações e condições estabelecidas nos padrões de emissão e de qualidade. Atendidos tais padrões, não se fala em poluição (art. 3ํㅗ III, "e", da Lei Federal 6.938/81) nem, a rigor, em dano ambiental. ${ }^{295}$

Como visto, ainda, os padrões foram fixados para assegurar, em grande medida, a saúde e a comodidade humanas, variando conforme o uso previsto

292 "Com relação ao sistema brasileiro, pensa-se ser possível invocar o princípio da proporcionalidade quando o benefício a ser obtido com a restauração natural não for significativo diante de seus elevados custos. (...) Ademais, exige-se que a medida escolhida seja tecnicamente exequível, de acordo com os recursos tecnológicos e financeiros disponíveis" (STEIGLEDER, 2017, p. 226).

${ }^{293}$ Aponta-se que, diferentemente da tradição brasileira, o sistema jurídico alemão, em geral, preza pela exequibilidade de suas normas (inclusive constitucionais) e evita enunciados de conteúdo utópico, distante da realidade administrativa e econômica. Nesse sentido, registre-se a oposição de autores alemães à inserção, na Constituição, de um direito fundamental a um "meio ambiente saudável" (KRELL, 2003, p. 179).

294 "Se partirmos do extremismo, toda ocupação humana causa impacto ambiental. Por isso a necessidade de atuação estatal, quer por meio da normatização, quer por meio do exercício de poder de polícia, em consonância com a razoabilidade e proporcionalidade" (TJSP, Apelação no 1032789-75.2013.8.26.0100, Des. Ruy Alberto Leme Cavalheiro, 1ª Câmara Reservada ao Meio Ambiente, j. 03.03.16).

295 "A poluição permitida pelos padrões de emissão de poluentes é considerada como mero 'incômodo', não se revestindo da 'gravidade' necessária à configuração do dano ambiental' (STEIGLEDER, 2017, p. 113) 
para cada região ou corpo hídrico. A depender, portanto, do uso, serão admitidas concentrações maiores ou menores de contaminantes.

Importante ressaltar aqui que os padrões não se confundem com os valores orientadores utilizados no gerenciamento de áreas contaminadas. Embora ambos sejam utilizados para controlar a presença de contaminantes nos diferentes meios, cada um está inserido em sistemática própria: eventual ultrapassagem dos padrões é, em princípio, proibida ${ }^{296}$ e poderia dar ensejo à adoção de medidas voltadas à reparação do dano ambiental presumido; eventual ultrapassagem dos valores orientadores, por sua vez, obriga o responsável legal a seguir com o diagnóstico da área contaminada e, somente verificada situação de risco intolerável aos receptores expostos, é que será exigida a adoção de medida de intervenção.

No caso de áreas contaminadas, portanto, a caracterização da poluição/dano ambiental não é tão simples como no caso do ar ou da água, sendo possível cogitar que só haveria dano e a necessidade de repará-lo diante da confirmação do risco aos receptores expostos (art. 36 do Decreto SP 59.263/13). Trata-se de questão delicada que pode ser analisada com cuidado em estudo próprio. ${ }^{297}$

Admitida a hipótese de que, no contexto de áreas contaminadas, a confirmação do risco intolerável atrairia o conceito jurídico de dano ambiental, seria possível considerar que a adoção de medidas voltadas ao afastamento ou redução do risco a níveis toleráveis seria suficiente para a reparação do dano.

Independentemente do que caracterizaria o dano ambiental no contexto de áreas contaminadas, porém, é preciso avaliar se as medidas previstas nas normas do GAC podem ser consideradas adequadas para reparar o dano.

A esse respeito, vale anotar que, como visto no item 4.1.2., em função de características intrínsecas às próprias atividades poluidoras e de aspectos

\footnotetext{
296 MACHADO, 2016, p. 414.

297 Há quem defenda que, no caso das áreas contaminadas, a caracterização do dano reparável seja informada, em um primeiro plano, pelos valores de intervenção, sendo "imprescindível, à luz dos princípios da prevenção e da precaução, a realização de investigações mais detalhadas que considerem, no caso concreto, o impacto das contaminações residuais na saúde das pessoas e nos ecossistemas, inclusive com projeções de riscos futuros, salientando-se a importância de as pessoas atingidas serem informadas, de forma clara, acessível e completa, sobre a existência desses riscos, a fim de que possam participar dos processos decisórios sobre as medidas de controle futuro e de remediação" (STEIGLEDER, 2012, p. 310).
} 
socioeconômicos, diversas normas de reparação de dano ambiental não exigem o retorno ao status quo ante, admitindo a adoção de medidas tecnicamente aprovadas pelos órgãos ambientais competentes. É o caso, por exemplo, da recuperação de áreas degradadas e da recomposição de APP e reserva legal mediante a utilização de espécies exóticas e de técnicas agroflorestais.

Diante disso, o fato de as normas do GAC não exigirem a remoção completa dos contaminantes em todo e qualquer caso e serem mais ou menos rigorosas conforme o uso previsto e a sensibilidade dos receptores expostos não nos parece, em princípio, incompatível com a sistemática de proteção ambiental do ordenamento jurídico brasileiro.

Quanto a eventual colisão da concepção do GAC com princípios do direito ambiental, aponta-se que, a rigor, uma norma positivada sempre prevalece sobre um princípio setorial, já que princípios setoriais, embora orientadores, não teriam o poder de afastar normas do ordenamento jurídico - ao contrário da Constituição Federal e do reconhecimento de eventual inconstitucionalidade. ${ }^{298}$ Como, até o momento, a inconstitucionalidade do GAC não foi declarada, suas normas prevaleceriam em eventuais conflitos com princípios setoriais.

Ainda assim, a análise da relação entre as normas do GAC com determinados princípios do direito ambiental pode ser interessante para o próprio aprimoramento e/ou consolidação do modelo ora adotado.

Como visto no item 4.1., o princípio da reparação integral, tal como delineado pelo STJ, sugere que os danos ambientais devem ser reparados da forma mais completa possível, idealmente in natura e, no limite, verificados danos considerados irreversíveis, inclusive interinos e morais coletivos, por meio de indenização.

Aqui, o raciocínio da adequação das medidas propostas para a reparação do dano é relevante inclusive para o cálculo de eventual indenização.

Se a adequação da medida reparadora for condicionada, em regra, ao retorno do status quo ante, os danos ambientais (e a necessidade de reparar/indenizar) poderão persistir mesmo com a observância das normas legais

298 "Ante a possível existência de conflito entre uma norma legal expressa e um princípio setorial, há que prevalecer a norma positivada, salvo se ela se apresentar maculada pela insconstitucionalidade. Observe-se que, no caso, não se trata propriamente da prevalência de um princípio setorial, mas de uma afronta à Constituição, o que é uma preliminar inafastável' (ANTUNES, 2011, p. 39). 
e das soluções técnicas indicadas pelos órgãos ambientais - seja no GAC, seja na recuperação de áreas degradadas ou na recomposição florestal.

Como referido no item 4.1.2., o cálculo de indenizações por danos ambientais é complexo em função da necessidade de se desenvolver metodologia adequada para valoração dos respectivos prejuízos, representando hoje elemento de incerteza. Além disso, não há muita clareza sobre quem deveria pagar tais indenizações - se apenas o poluidor ou também quem mais for obrigado a adotar medidas de reparação (o adquirente da área poderia ser obrigado a indenizar danos interinos ou morais coletivos, por exemplo?).

Será preciso verificar de que modo os tribunais aplicarão o princípio da reparação integral para analisar de que forma ele se relacionaria com o GAC.

A depender do posicionamento dos tribunais quanto (i) à adequação das medidas do GAC para a reparação de danos ambientais, (ii) ao responsável pelo pagamento de indenizações e (iii) ao valor de tais indenizações, parte dos méritos do modelo adotado - viabilizar a reutilização segura das áreas contaminadas sem comprometer os recursos públicos de forma considerada irracional - poderá ficar prejudicada. ${ }^{299}$

Embora a reutilização de áreas contaminadas e abandonadas seja promovida, essencialmente, por investimentos do setor imobiliário ${ }^{300}$, vale anotar que, na ausência de responsáveis ou na sua omissão, a reabilitação de tais áreas fica a cargo do Poder Público. ${ }^{301}$

Neste ponto cabem algumas considerações sobre a aplicação do PPP:

299 "Deve-se observar com ponderação o princípio da reparação integral do meio ambiente, uma vez que, no caso dos autos, a área impugnada, à área em que houve a contaminação do subsolo e águas subterrâneas, era utilizada para fins industriais, procedendo as corrés a sua remediação para modificar o uso do solo para residencial. Caso se imponha obrigação onerosamente excessiva, o terreno, que já se encontrava contaminado por anterior atividade industrial, assim permaneceria, sem qualquer estímulo ao adquirente para proceder à remediação da área contaminada e sua posterior reutilização" (TJSP, Apelação oㅡ 104469912.2014.8.26.0053, voto convergente do Des. Luis Fernando Nishi, $2^{\text {a }}$ Câmara Reservada ao Meio Ambiente, j. 23.10.17).

300 MATTEI, 2010, p. 99.

301 Em âmbito federal, a Política Nacional de Resíduos Sólidos atribuiu ao Governo Federal, sem prejuízo de outras esferas governamentais, a obrigação de promover a descontaminação das áreas órfãs, assim entendidas aquelas "cujos responsáveis pela disposição não sejam identificáveis ou individualizáveis" (arts. 3ํ, III, e 41 da Lei Federal 12.305/10). No Estado de São Paulo, diante da omissão do responsável legal, a CETESB poderá tomar as providências necessárias no âmbito do GAC e exigir posterior ressarcimento; em determinados casos poderão ser utilizados os recursos do FEPRAC, a fundo perdido (arts. 96 e 70 do Decreto SP 59.263/13). 
Em se tratando de áreas contaminadas históricas, o desconhecimento e a insolvência dos poluidores ${ }^{302}$ dificulta a aplicação do PPP. De fato, a internalização dos custos de reabilitação por empresas falidas ou que já não existem mais pode ser inviável.

Talvez em função de tal dificuldade é que a Lei SP 13.577/09 tenha ido além do poluidor, apontando como responsáveis solidários pelo gerenciamento de uma área contaminada o poluidor, seus sucessores, o proprietário da área, o possuidor, o superficiário e qualquer um que dela se beneficie (art. 13).

A aplicação do PPP na prevenção de áreas contaminadas, por outro lado, não envolve a mesma dificuldade, bastando que os potenciais poluidores realizem o monitoramento preventivo indicado no GAC (art. 17 do Decreto SP 59.263/13 e Anexo I da Decisão de Diretoria 38/17 da CETESB). Tais medidas, aliadas à fiscalização dos órgãos ambientais, talvez sejam tão ou mais importantes do que aquelas voltadas à reabilitação.

Nesse contexto, e a exemplo do que foi proposto na Holanda e na Alemanha, talvez seja pertinente estabelecer metas diferenciadas para a reabilitação de contaminações históricas e recentes, já que nestas o poluidor poderia ser identificado com mais facilidade e, ao menos em princípio, teria maior consciência dos prejuízos advindos da contaminação do solo e da água subterrânea e maior possibilidade de evita-los.

O princípio da precaução, por sua vez, tal como definido pelo STF (RE 627.189/SP), nos parece alinhado com o GAC, na medida em que, mesmo diante da incerteza quanto à nocividade das diversas substâncias presentes no solo e na água subterrânea, o GAC permite que se avaliem os riscos, os custos das medidas de prevenção e, ao final, se execute as ações necessárias, decorrentes de decisões motivadas, coerentes e proporcionais.

Como visto no item 4.3., a aplicação do princípio da precaução não significa necessariamente que, em um contexto de incerteza científica, as atividades serão proibidas, significando, antes, que em tal contexto as decisões

302 STEIGLEDER, 2003, p.128. 
deverão ser tomadas após um procedimento de identificação e avaliação de riscos. ${ }^{303}$ Trata-se da gestão dos riscos, tal como proposto no GAC.

Vale anotar, por fim, que o meio ambiente natural não é o único bem jurídico tutelado quando se fala em reabilitação de áreas contaminadas, havendo também o meio ambiente artificial e sua dinâmica urbana. ${ }^{304}$

Como visto no item 4.4, a utilização adequada - e, assim, o exercício da função social - da propriedade urbana é tão importante para as cidades, que um imóvel subutilizado poderá ser objeto de parcelamento ou edificação compulsórios, cobrança de IPTU progressivo e desapropriação.

Ao viabilizar a reutilização de áreas contaminadas, portanto, o GAC possibilita o exercício da função social urbana dos respectivos imóveis e a realização das bases do urbanismo moderno (habitação, trabalho, recreação e circulação). ${ }^{305}$

Em que pesem os avanços que a legislação paulista representou na proteção de solos e de águas subterrâneas, 306 o GAC está em constante revisão e aperfeiçoamento (haja vista a edição, em 2016, de novos valores orientadores e, em 2017, de nova Decisão de Diretoria da CETESB sobre o assunto), sendo importante o envolvimento de diversos agentes na discussão sobre metas de reabilitação, 307 inclusive para a eventual edição de outras leis estaduais ou lei federal sobre o tema.

A nosso ver, as críticas feitas ao GAC poderiam ser feitas também a outras normas brasileiras de proteção ambiental: a fixação dos padrões não leva em

303 "A implementação do princípio da precaução não tem por finalidade imobilizar as atividades humanas. Não se trata da precaução que tudo impede ou que em tudo vê catástrofes ou males. (...) O princípio da precaução não se aplica sem um procedimento prévio de identificação e de avaliação de riscos" (MACHADO, 2016, pp. 90 e 732).

304 "O exercício do dever de agir não deve levar em consideração apenas o direito ao meio ambiente ecologicamente equilibrado ou da reparação integral. Também deve ser considerado o desenvolvimento sustentável, o direito de propriedade e as normas urbanísticas que permitem a ocupação do solo" (TJSP, Apelação oㅜ 1032789-75.2013.8.26.0100, Des. Ruy Alberto Leme Cavalheiro, $1^{\text {a }}$ Câmara Reservada ao Meio Ambiente, j. 03.03.16).

305 ALVES, 2013, p. 242. Ainda de acordo com a autora, "seja a propriedade urbana ou rural a função social será cumprida se houver uma utilidade social'.

306 LUTTI, 2012, p. 15.

307 "A sociedade deve discutir qual uso deseja para a área em discussão, associado à profundidade com a qual quer que a remediação seja feita. As duas variáveis estão sempre interligadas, pelo que a direção técnica dos debates deverá, desde o início do processo, tornar claro aos partícipes este aspecto, uma vez que os custos recairão direta ou indiretamente na população" (TOLEDO, 2007, p. 147). 
conta a reação entre os diferentes poluentes emitidos ${ }^{308}$, o enquadramento da Resolução CONAMA 357/05 admite que um corpo de água doce seja destinado apenas aos usos de navegação e paisagístico (Classe IV), comprometendo-se outras funções potenciais do recurso hídrico, etc. A rigor, portanto, não nos parece que o GAC seria incompatível com o ordenamento jurídico posto. Nada impede, contudo, que o sistema seja revisitado ou que, mantida a sistemática, o nível de tolerabilidade aos diferentes impactos ambientais seja revisto e a legislação, atualizada.

308 "O problema envolvendo os padrões de emissão como critério para definir a gravidade e relevância do dano diz respeito ao fato de que a dose máxima tolerável é geralmente fixada para cada poluente, considerado isoladamente, sem atenção para o fenômeno de sinergia entre os vários tipos de substâncias nocivas que se misturam na natureza e se acumulam nos organismos vivos" (STEIGLEDER, 2017, p. 117). 


\section{BIBLIOGRAFIA}

ALVES, Elizete Lanzoni. A Proteção Ambiental e a Instrumentalidade da Averbação Informativa de Áreas Contaminadas no Registro de Imóveis: uma perspectiva da accountability ambiental na Sociedade de Risco. Tese de doutorado apresentada ao Centro de Ciências Jurídicas da Universidade Federal de Santa Catarina, Florianópolis, 2013.

ANTUNES, Paulo de Bessa. Dano Ambiental: uma abordagem conceitual. $2^{\underline{a}}$ ed. Rio de Janeiro: Lumen Juris, 2015.

ANTUNES, Paulo de Bessa. Direito Ambiental. 16 edição. São Paulo: Atlas, 2011.

ANTUNES, Paulo de Bessa. Política Nacional do Meio Ambiente PNMA comentários à Lei 6.938 de 31 de agosto de 1981. Rio de Janeiro: Lumen Juris, 2005.

ARAGÃO, Maria Alexandra de Sousa. O princípio do poluidor pagador - pedra angular da política comunitária do ambiente. Coimbra: Coimbra, 1997.

ARAGÃO, Maria Alexandra de Sousa. Direito Comunitário do Meio Ambiente. Cademos CEDOUA. Coimbra: Livraria Almedina, 2002.

BARROS, Luiza Helena dos Santos. Requalificação dos aterros desativados (brownfields) no Município de São Paulo: parques (greenfields) Raposo Tavares e Jardim Primavera. Tese de doutorado apresentada à Faculdade de Arquitetura e Urbanismo da Universidade de São Paulo, 2011.

BECHARA, Erika. Licenciamento e compensação ambiental na Lei do Sistema Nacional das Unidades de Conservação (SNUC). São Paulo: Atlas, 2009. 
BICALHO, Rodrigo Cury; LOPES, Nathalia Lima Feitosa. A remediação das áreas contaminadas: uma abordagem jurídica e social. Revista de Direito Ambiental, vol. 71, ano 18, jul-set/2013. Revista dos Tribunais. pp. 217-243.

BICUDO, Pedro Marino. Direito urbanístico e áreas contaminadas: um contraponto à tese da "reparação integral". In ALMEIDA, Marcelo Manhães de; LEVY, Wilson (coord.). Temas Fundamentais de Direito Imobiliário e Urbanístico. São Paulo: Quartier Latin, 2017. pp. 133-149.

CUNHA, Rodrigo César de Araújo. Avaliação de risco em áreas contaminadas por fontes industriais desativadas - estudo de caso. Tese de doutorado apresentada ao Instituto de Geociências da Universidade de São Paulo, 1997.

CUNHA, Rodrigo César de Araújo. Prefácio. In MORAES, Sandra Lúcia de; TEIXEIRA, Cláudia Echevenguá; MAXIMIANO; Alexandre Magno de Sousa (org.). Guia de elaboração de planos de intervenção para o gerenciamento de áreas contaminadas. São Paulo: IPT: BNDES, 2014.

DERANI, Cristiane. Direito Ambiental Econômico. 3를 ed. São Paulo, Saraiva, 2008.

FERGUSON, Colin C. Assessing risks from contaminated sites: policy and practice in 16 european countries. Land Contamination \& Reclamation, Vol. 7, No. 2, 1999. Disponível em <http://www.clarinet.at/library/index.htm>.

FIORILLO, Celso Antonio Pacheco. Curso de direito ambiental brasileiro. 17ª ed. São Paulo: Saraiva, 2017.

FREITAS, Gilberto Passos; GRANZIERA, Maria Luiza Machado. Padrões de qualidade ambiental e crime de poluição. In Tópicos de Direito Ambiental: 30 anos da Política Nacional do Meio Ambiente / Rômulo S. R. Sampaio, Guilherme J. S. Leal, Antonio Augusto Reis (org.). Rio de Janeiro: Lumen Juris, 2011. pp. 187211. 
GLOEDEN, Elton. Gerenciamento de Áreas Contaminadas na Bacia Hidrográfica do Reservatório Guarapiranga. Tese de Doutorado apresentada ao Instituto de Geociências da Universidade de São Paulo, 1999.

GRANZIERA, Maria Luiz Machado. Direito Ambiental. 4ª ed. São Paulo: Atlas, 2015.

HABERMANN, Mateus. Requalificação urbana em áreas contaminadas na cidade de São Paulo. Estudos avançados [0103-4014], 2014, disponível em <http://dx.doi.org/10.1590/S0103-40142014000300008>

HOLZWARTH, Fritz; RADTKE, Hansjörg; HILGER, Bernd; BACHMANN, Günther. Bundes-Bodenschutzgesetz / Bundes-Bodenschutz- und Altlastenverordnung: Handkommentar. Berlim: Erich Schmitd, 2000.

KLOEPFER, Michael. Umwelrecht. $3^{\underline{a}}$ ed. Munique: Verlag C.H. Beck, 2004.

KNOPP, Lothar. Altlastenrecht in der Praxis: unter Berücksichtigung des Rechts der neuen Bundesländer. Herne / Berlim: Verlag für die Rechts- und Anwaltspraxis, 1992.

KRELL. Andreas J. Ordem Jurídica e Meio Ambiente na Alemanha e no Brasil: alguns aspectos comparativos. Revista de Direito Ambiental, vol. 31, ano 8, julset/2003. Revista dos Tribunais. pp.178-206.

KRIEGER, Stefanie Ann Anita: Die Verantwortlichkeit für die Sanierung von Altlasten und schädlichen Bodenveränderungen nach dem BundesBodenschutzgesetz. Baden-Baden: Nomos, 2008.

KÜHN, Wolfgang. Die Amtshaftung der Gemaindenwegen der Überplanung von Altlasten. Berlim: Duncker\&Humblot, 1997. 
LIEDEKERKE, Marc van; PROKOP, Gundula; RABL-BERGER, Sabine; KIBBLEWHITE, Mark; LOUWAGIE, Geertrui. Progress in the management of Contaminated Sites in Europe. JRC Reference Reports. European Union, 2014.

LEMOS, Patrícia Faga Iglecias. Meio ambiente e responsabilidade civil do proprietário: análise do nexo causal. São Paulo: Revista dos Tribunais, 2008.

LOPEZ, Teresa Anacona. Princípio da precaução e evolução da responsabilidade civil. São Paulo: Quartier Latin, 2010.

LUTTI, José Eduardo Ismael. Resolução CONAMA 420/2009 e Lei estadual 13.577/2009: inconstitucionalidade da "remediação para uso declarado". Revista de Direito Ambiental, vol. 65, ano 17, jan-mar/2012. Revista dos Tribunais. pp.1325.

MACHADO, Paulo Affonso Leme. Direito Ambiental Brasileiro. 24를 ed. São Paulo: Malheiros, 2016.

MAGALHÃES, Jeanete Solange Braga. Avaliação da gestão de sítios contaminados por resíduos perigosos nos EUA, Canadá, Países Europeus e Brasil, e exemplo de um manual simplificado de avaliação de saúde ambiental destes sítios para o Brasil. Dissertação apresentada à Escola Nacional de Saúde Pública da Fundação Oswaldo Cruz, 2000.

MARKER, Andreas. A revitalização de áreas urbanas degradadas - Políticas, instrumentos e incentivos no cenário internacional. Relatório de Consultoria 01/01. São Paulo: GTZ, 2003.

MARKER, Andreas. Avaliação ambiental de terrenos com potencial de contaminação: gerenciamento de riscos em empreendimentos imobiliários. Brasília: CAIXA, 2008. 
MATTEI, Juliana Flávia. Revitalização de brownfields: da aplicação do princípio da função socioambiental da propriedade ao gerenciamento de áreas contaminadas ou suspeitas de contaminação. Dissertação apresentada ao Programa de PósGraduação e Pesquisa da Universidade de Caxias do Sul, 2010.

MELO, Melissa Ely. O dever jurídico de restauração ambiental - percepção da natureza como projeto. Dissertação apresentada à Universidade Federal de Santa Catarina, 2008.

MILARÉ, Édis. Direito do ambiente. 10 ${ }^{\underline{a}}$ ed. São Paulo: Revista dos Tribunais, 2015.

MIRRA, Álvaro Luiz Valery. Princípios do Direito Ambiental. Revista de Direito Ambiental, vol. 2, ano 1, abr/jun de 1996. Revista dos Tribunais. pp. 50-66.

MIRRA, Álvaro Luiz Valery. Ação civil pública e a reparação do dano ambiental. $2^{\underline{a}}$ ed. São Paulo: Juares de Oliveira, 2004.

MORAES, Sandra Lúcia de; TEIXEIRA, Cláudia Echevenguá; MAXIMIANO; Alexandre Magno de Sousa (org.). Guia de elaboração de planos de intervenção para o gerenciamento de áreas contaminadas. São Paulo: IPT: BNDES, 2014.

MORINAGA, Carlos Minoru. Áreas contaminadas e a construção da paisagem pós-industrial na cidade de São Paulo. Tese de doutorado apresentada à Faculdade de Arquitetura e Urbanismo da Universidade de São Paulo, 2013.

NUSDEO, Ana Maria de Oliveira. Pagamento por serviços ambientais: sustentabilidade e disciplina jurídica. São Paulo: Atlas, 2012.

OLIVEIRA, Claudio Pereira de. Águas subterrâneas - fontes legais e seguras de abastecimento. Caderno Técnico 꾸 5. São Paulo: Associação Brasileira de Águas Subterrâneas - ABAS, 2012. 
RAMIRES, Jane Zilda dos Santos. Áreas contaminadas e os riscos socioambientais em São Paulo. Dissertação apresentada à Faculdade de Filosofia, Letras e Ciências Humanas do Departamento de Geografia da Universidade de São Paulo, 2008.

RAMIRES, Jane Zilda Dos Santos; RIBEIRO, Wagner Costa. Gestão dos Riscos Urbanos em São Paulo: as áreas contaminadas. Confins, Iss 13, 2011, disponível em <http://confins.revues.org/7323>

ROCHA, Luis Fernando. Áreas contaminadas: a reparação integral do dano e o equilíbrio de resiliência ecológica. Revista de Direito Ambiental, vol. 80, ano 20, out-dez/2015. Revista dos Tribunais. pp. 135-171.

RODRIGUES, Marcelo Abelha. Elementos de direito ambiental: parte geral. $2^{\underline{a}}$ ed. São Paulo: Revista dos Tribunais, 2005.

RUCHAY, Dietrich; KÜHNEL, Gerd: Altlastensanierung aus politischer Sicht. In GOSSOW, Volkmar. Altlastensanierung: Genehmigungsrechtliche, bautechnische und haftungsrechtliche Aspekte. Wiesbaden e Berlim: Bauverlag GmbH, 1992.

SAMPAIO, Francisco José Marques. Responsabilidade civil e reparação de danos ao meio ambiente. Rio de Janeiro: Lumen Juris, 1998.

SÁNCHEZ, Luis Enrique. Desengenharia: o passivo ambiental na desativação de empreendimentos industriais. São Paulo: Editora da Universidade de São Paulo, 2001.

SCHULZ, Ronald: Die Lastentragung bei der Sanierung von Bodenkontaminationen. Berlim: Duncker \& Humbold, 1995.

SILVA, Anna Carolina Marques Ayres da. A importância dos fatores ambientais na reutilização de imóveis industriais em São Paulo. Dissertação apresentada à Escola Politécnica da Universidade de São Paulo, 2002. 
SILVA, Anna Carolina Marques Ayres da et al. Guia para avaliação do potencial de contaminação em imóveis. São Paulo: CETESB: GTZ, 2003.

SILVA, Danny Monteiro da. Dano ambiental e sua reparação. Curitiba: Juruá, 2006.

SOARES, Marilda de Souza. Áreas contaminadas e águas subterrâneas na Unidade de Gerenciamento de Recursos Hídricos do Alto Tietê. Tese de doutorado apresentada à Faculdade de Saúde Pública da Universidade de São Paulo, 2013.

SPINOLA, Ana Luiza Silva. Inserção das áreas contaminadas na gestão municipal: desafios e tendências. Tese de doutorado apresentada à Faculdade de Saúde Pública da Universidade de São Paulo, São Paulo, 2011, disponível em <http://www.teses.usp.br/teses/disponiveis/6/6134/tde-03112011-172059/>

STEIGLEDER, Annelise Monteiro. Áreas contaminadas e a obrigação do poluidor de custear - um diagnóstico para dimensionar o dano ambiental. Revista de Direito Ambiental, vol. 25, ano 7, jan-mar/2002. Revista dos Tribunais. pp. 59-78.

STEIGLEDER, Annelise Monteiro. Aspectos jurídicos da reparação de áreas contaminadas por resíduos industriais. Revista de Direito Ambiental, vol. 29, ano 8, jan-mar/2003. Revista dos Tribunais. pp. 127-166.

STEIGLEDER, Annelise Monteiro. Responsabilidade civil ambiental: as dimensões do dano ambiental no direito brasileiro. $3^{\underline{a}}$ ed. Porto Alegre: Livraria do Advogado Editora, 2017.

STEIGLEDER, Annelise Monteiro. Responsabilidade civil e gestão de áreas contaminadas no Brasil. In Dano ambiental na sociedade de risco/ coordenador José Rubens Morato Leite; organizadoras Heline Silvini Ferreira, Maria Leonor Paes Cavalcanti Ferreira. São Paulo: Saraiva, 2012, pp. 271-313. 
TOLEDO, Manoel Paulo de. Proposta de metodologia para estabelecimento de uso e ocupação do solo em áreas contaminadas. Dissertação apresentada à Escola Politécnica da Universidade de São Paulo, 2007.

VERSTEYL, Ludger-Anselm; SONDERMANN, Wolf Dieter: Bundesbodenschutzgesetz - Kommentar. Munique: Verlag C.H. Beck, 2005.

WICHERT, Hans-W.: Altlasten: Alte Lasten - neue Aufgaben! In GOSSOW, Volkmar. Altlastensanierung: Genehmigungsrechtliche, bautechnische und haftungsrechtliche Aspekte. Wiesbaden und Berlin: Bauverlag GmbH, 1992. 